\title{
A novel synthetic compound shows antioxidant and anti- inflammatory activity and alleviates cognitive deficits in rats for the treatment of Alzheimer's disease
}

\author{
Jing Xie ${ }^{1}$, Rui Su${ }^{2}$, Danna Wu ${ }^{1}$, Yeyu Qin ${ }^{1}$, Xiong Yun ${ }^{1}$ \\ ${ }^{1}$ Department of Pharmacy, Hainan General Hospital (Hainan Affiliated Hospital of Hainan Medical University), Haikou, China; ${ }^{2}$ School of \\ Pharmaceutical Sciences, Sun Yat-sen University, Guangzhou, China \\ Contributions: (I) Conception and design: J Xie, R Su; (II) Administrative support: Y Qin; (III) Provision of study materials or patients: R Su; (IV) \\ Collection and assembly of data: J Xie, R Su; (V) Data analysis and interpretation: D Wu, X Yun; (VI) Manuscript writing: All authors; (VII) Final \\ approval of manuscript: All authors. \\ Correspondence to: Jing Xie. Department of Pharmacy, Hainan General Hospital (Hainan Affiliated Hospital of Hainan Medical University), No. 19, \\ Xiuhua Road, Haikou 570311, China. Email: van_joric@163.com.
}

Background Alzheimer's disease (AD) is a progressive dementia, and $\beta$-amyloid (A $\beta$ ) accumulation is widely regarded as the primary pathogenesis of $\mathrm{AD}$. A new synthetic compound, 8-hydroxyquinolineresveratrol derivative (E)-5-(4-hydroxystyryl)quinolin-8-ol (10c) was evaluated as a possible anti-AD agent.

Method: (I) The total amount of ROS in SH-SY5Y cells was detected by dichlorofluorescein diacetate (DCFH-DA), and the antioxidant activity and neuroprotective effect of 10c in SH-SY5Y cells were evaluated; (II) Griess reagent was used to test the activity of Compound 10c against NO production in LPSinduced BV-2 microglial cells; (III) An automatic digital stereotaxic instrument was used to inject $A \beta_{25-35}$ into the brain to establish an $\mathrm{AD}$ animal model to evaluate the protective effect of compound $10 \mathrm{c}$ on $\mathrm{A} \beta_{25-35^{-}}$ induced learning and memory dysfunction in rats.

Results: 10c exhibited far more potent antioxidant activity for both exogenous and endogenous reactive oxygen species (ROS) than trolox, resveratrol, and CQ (ROS production: $10 \mathrm{c}$ with $26.23 \%$ at $1.5 \mu \mathrm{M}$; resveratrol with $82.17 \%$ at $2.5 \mu \mathrm{M}$; CQ with $78.52 \%$ at $10 \mu \mathrm{M})$. $10 \mathrm{c}$ also shows good neuroprotective effects as an endogenous antioxidant in neuroblastoma cells. Moreover, Compound 10c also demonstrated effective inhibition of nitric oxide (NO) production $\left(\mathrm{IC}_{50}=3.10 \mu \mathrm{M}\right)$ and $\mathrm{IL}-1 \beta$ production in $\mathrm{BV}-2$ microglial cells which were treated with lipopolysaccharide (LPS). In the water maze test, the numbers of rats who crossed the former platform were increased significantly in both the $10 \mathrm{c}$ group $(5.7 \pm 1.6)$ and positive control group (CQ, 5.1 \pm 1.7$)$. Meanwhile, both $10 \mathrm{c}(43.8 \pm 5.5 \mathrm{~s})$ and CQ $(44.1 \pm 6.6 \mathrm{~s})$ treatment could significantly prolong the time rats spent in the target quadrant compared to the vehicle-treated model group. These results demonstrated that $10 \mathrm{c}$ could alleviate the learning and memory dysfunction of rats induced by $\mathrm{A} \beta_{25-35}$ to a certain extent.

Conclusions: Altogether, compound $10 \mathrm{c}$ is a promising compound for the treatment of AD.

Keywords: Alzheimer's disease (AD); anti-oxidation; anti-inflammation; Morris water maze

Submitted Jun 23, 2021. Accepted for publication Sep 10, 2021.

doi: $10.21037 / \mathrm{apm}-21-1983$

View this article at: https://dx.doi.org/10.21037/apm-21-1983 


\section{Introduction}

Alzheimer's disease (AD) is the most common fatal neurodegenerative disease of older people, and is characterized by loss of memory, cognitive decline, and behavioral abnormalities, eventually leading to death (1). Although the pathogenesis of AD is not fully known, certain hallmarks including $\beta$-amyloid ( $\mathrm{A} \beta$ ) deposits, which form extracellular senile plaques, along with cerebral atrophy and intracellular neurofibrillary tangles (NFT) are reported to play prominent roles in the development of $\mathrm{AD}$ (2). In the past decades, scientists have developed many approaches to treat $\mathrm{AD}$. However, there is no effective medicine that can definitively cure or delay the process of AD (3).

$\mathrm{A} \beta$ accumulation is widely regarded as the primary pathogenesis of $\mathrm{AD}$ (4). There is also considerable evidence to support the toxic role of $\mathrm{A} \beta$ oligomers in neuronal death (5). Recent studies reported that increased toxic A $\beta$ oligomers induced inflammation in glial cells, as well as increased the expression and production of inflammatory mediators, such as nitric oxide (NO), interleukin-1 $\beta$ (IL-1 $\beta$ ), and tumor necrosis factor $\alpha(\mathrm{TNF}-\alpha)(6-8)$. In addition, $\mathrm{A} \beta$-induced oxidative stress refers to cell overoxidation leading to cellular damage, which is carried out by reactive oxygen species (ROS) $(9,10)$. Oxidative damage could lead to mitochondrial dysfunction and cell lysis in $\mathrm{AD}(11,12)$. Thus, drugs that scavenge oxygen radicals and reduce the production of inflammatory mediators are speculated to prevent or treat $\mathrm{AD}$ to some extent $(13,14)$.

A series of 8-hydroxyquinoline-resveratrol derivatives, which were obtained by combining resveratrol with the metal chelator clioquinol (CQ), were reported to act as antioxidants, biometal chelators, and inhibitors of $\mathrm{A} \beta$ aggregation. In particular, (E)-5-(4-hydroxystyryl)quinolin8-ol (10c) (Figure 1), a multi-target-directed small molecules against $\mathrm{AD}$, showed potential anti-oxidant behaviour, good metal chelating ability, inhibition of copper(II)-induced A $\beta$ aggregation with ability to cross blood-brain barrier (15). In this paper, in order to study the pharmacological effects and possible mechanism of 10c in Alzheimer's disease, we further evaluated the antioxidant activity and antiinflammatory activity of $10 \mathrm{c}$, and also studied the anti-AD effect of $10 \mathrm{c}$ in an animal model. A protocol was prepared before the study without registration. We present the following article in accordance with the ARRIVE reporting checklist (available at https://dx.doi.org/10.21037/apm-211983).

\section{Methods}

\section{Culture of SH-SY $5 Y$ cells and BV-2 cells}

The human neuroblastoma cell line SH-SY5Y (Laboratory Animal Service Center at Sun Yat-sen University) was cultured in a 1:1 mixture of F-12 nutrient mixture (Ham12) and Eagle's MEM containing 15 nonessential amino acids, $10 \%$ heat-inactivated fetal bovine serum (FBS, GIBCO, Invitrogen, USA), $50 \mathrm{mg} / \mu \mathrm{L}$ penicillin, $50 \mathrm{mg} / \mu \mathrm{L}$ streptomycin, and $1 \mathrm{mM}$ glutamine. Cultures were maintained in a humidified incubator at $37^{\circ} \mathrm{C}$ with $5 \%$ $\mathrm{CO}_{2}$ and $95 \%$ air. For assays, SH-SY5Y cells were plated into 96-well plates $\left(1 \times 10^{4}\right.$ cells/well).

BV-2 microglial cells (BeNa Culture Collection, BNCC) were routinely grown in a humidified incubator at $37{ }^{\circ} \mathrm{C}$ with $5 \% \mathrm{CO}_{2}$ and $95 \%$ air in Dulbecco's modified Eagle's medium (DMEM, GIBCO) containing 10\% heatinactivated FBS (GIBCO), $50 \mathrm{mg} / \mu \mathrm{L}$ penicillin, $50 \mathrm{mg} / \mu \mathrm{L}$ streptomycin, and $1 \mathrm{mM}$ glutamine. For assays, BV-2 cells were plated into 96 -well plates $\left(4 \times 10^{4}\right.$ cells/well).

\section{Determination of ROS}

SH-SY5Y cells were plated into 96-well plates at a density of $1 \times 10^{4}$ cells/well, and $24 \mathrm{~h}$ later the medium was substituted with the tested compounds and maintained for an additional $24 \mathrm{~h}$ at $37^{\circ} \mathrm{C}$. The cells were washed with phosphate buffer solution (PBS), then loaded with $5 \mu \mathrm{M}$ of DCFH-DA (a fluorescent probe) in PBS and incubated for $30 \mathrm{~min}$ at $37{ }^{\circ} \mathrm{C}$ in $5 \% \mathrm{CO}_{2}$. After removing DCFH-DA and washing, the cells were treated with $0.1 \mathrm{mM} t-\mathrm{BuOOH}$ (a compound to induce oxidative stress) in PBS for $30 \mathrm{~min}$. A multifunction microplate reader (Molecular Devices, Flex Station 3) was used to measure the fluorescence intensity of the cells from each well after incubation $\left(\lambda_{\text {ex }}=485 \mathrm{~nm}, \lambda_{\text {em }}=535 \mathrm{~nm}\right)$. The antioxidant activity, expressed as a percentage of the control cells, was calculated according to the formula (Ft-Fnt)/(Ft'Fnt) $\times 100$, where $\mathrm{Ft}=$ fluorescence intensity of neurons treated with the tested compound, Ft' = fluorescence intensity of neurons treated without the tested compound, and Fnt = fluorescence intensity of neurons untreated with $t$ - $\mathrm{BuOOH}$.

\section{Rotenone/oligomycin A-induced death of human neuroblastoma SH-SYSY cells}

The inhibitory effect of $10 \mathrm{c}$ on mitochondrial-triggered 


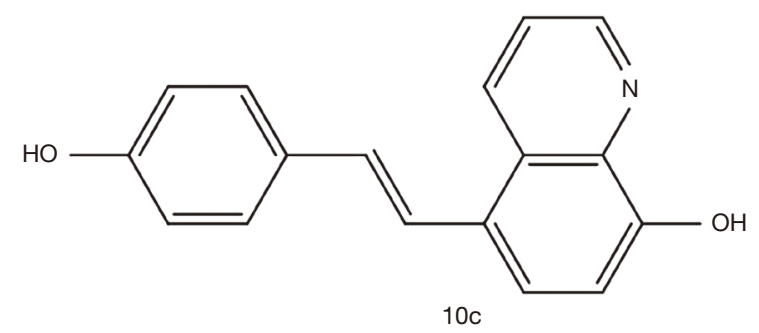

Figure 1 Structure of 10c.

endogenous oxidative stress induced by rotenone/ oligomycin A was evaluated with the human neuroblastoma cell line SH-SY5Y, while the mixture of rotenone and oligomycin A acted as the toxic insult $(16,17)$. SHSY5Y cells were exposed to $30 \mu \mathrm{M}$ rotenone plus $10 \mu \mathrm{M}$ oligomycin A for $24 \mathrm{~h}$ in the presence or absence of compound $10 \mathrm{c}$ and then measured with the MTT reduction method.

\section{Measurement of NO production}

The NO concentration was determined according to the Griess reaction $(18,19)$. BV-2 cells were plated into 96well plates at a density of $4 \times 10^{4}$ cells/well, and $24 \mathrm{~h}$ later cells were treated with $1.0 \mu \mathrm{g} / \mathrm{mL}$ lipopolysaccharide (LPS) in the presence or absence of compound 10c for $24 \mathrm{~h}$. Then, $50 \mu \mathrm{L}$ of culture supernatant was mixed with an equal volume of freshly prepared Griess reagent ( $1 \%$ sulfanilic acid in $5 \%$ phosphoric acid, $0.1 \% \mathrm{~N}-1$ naphthylethylenediamine) at room temperature in the dark. After $10 \mathrm{~min}$, the absorbance at $540 \mathrm{~nm}$ was determined by a multifunction microplate reader (molecular devices, flex station 3). Nitrite concentration was calculated with sodium nitrite as a standard. Inhibition $(\%)=\left[1-\left(\mathrm{A}_{\mathrm{LPS}+\text { sample }}\right.\right.$ $\left.\left.-\mathrm{A}_{\text {untreated }}\right) /\left(\mathrm{A}_{\text {LPS }}-\mathrm{A}_{\text {untreated }}\right)\right] \times 100$. These experiments were measured in quintuplicate, and the $\mathrm{IC}_{50}$ values were calculated using GraphPad Prism version 5.0. Quercetin was used as a positive control.

\section{Rat IL-1及 ELISA method}

The quantification of IL- $1 \beta$ was performed using the IL- $1 \beta$ immunoassay kit provided by R\&D Systems, which is a $4.5 \mathrm{~h}$ solid-phase ELISA designed to measure rat IL- $1 \beta$ levels. A rat IL-1 $\beta$ monoclonal antibody was pre-coated onto a microplate (20). The supernatant of BV-2 cells was treated with $1.0 \mu \mathrm{g} / \mathrm{mL}$ LPS in the presence or absence of compound 10c for $24 \mathrm{~h}$. Then, standards and samples were pipetted into the wells and any rat IL- $1 \beta$ present was bound by the immobilized antibody. After washing to remove any unbound substances, an enzyme-linked polyclonal antibody specific for rat IL- $1 \beta$ was added to the wells. Following washing away any unbound antibody-enzyme reagent, a substrate solution was added to the wells, and the intensity of the color produced, which was measured after the color development was stopped, was proportional to the amount of rat IL- $1 \beta$ bound in the initial step. The experiments were measured in quintuplicate and analyzed using GraphPad Prism version 5.0.

\section{Animal experiments}

\section{Chemicals and reagents}

$\mathrm{A} \beta_{25-35}$ (Cat: RP10008, Sigma) was dissolved in $5 \mu \mathrm{g} / \mathrm{\mu L}$ sterilized normal saline and cultured in an incubator at $37^{\circ} \mathrm{C}$ for 7 days to convert it to the neurotoxic form (aggregation form). Compound 10c and CQ were dissolved in $0.5 \%$ carboxymethyl cellulose sodium (CMC-Na) salt solution.

\section{Animals}

Forty Wistar male rats weighing 250-300 g were purchased from the laboratory animal center of Sun Yat-sen University (Guangzhou, China). The rats were randomly divided into 4 groups: the sham group, the model group, the CQ group $(21 \mathrm{mg} / \mathrm{kg})$, and the $10 \mathrm{c}(35 \mathrm{mg} / \mathrm{kg})$ group, with 10 rats in each group. Rats were provided with sterile food and water according to institutional guidelines, and raised on a $12 \mathrm{~h}$ light/dark cycle (light from 07:00 to 19:00) at a temperature of $20-22{ }^{\circ} \mathrm{C}$ and relative humidity of $60-70 \%$. Rats were fasted overnight and allowed free access to water before each experiment. Animal experiments were performed under a project license (No. 20175000102) granted by the ethics committee of Sun Yat-sen University, in compliance with Chinese national guidelines for the care and use of animals.

\section{Intrahippocampal injection of $\mathbf{A} \boldsymbol{\beta}_{25-35}$}

Stereotaxic surgery was performed under chloral hydrate (7\%, i.p.) anesthesia. $A \beta_{25-35}$ solution (aggregated form, $10 \mu \mathrm{g} / 2 \mu \mathrm{L})$ was injected by a microsyringe (10 $\mu \mathrm{L}$ gauge $)$ laterally into the hippocampal fissure. The stereotaxic coordinates of the injection were as follows: $\mathrm{AP}=-4.2 \mathrm{~mm}$, $\mathrm{L}=3.0 \mathrm{~mm}$ from the bregma, $\mathrm{H}=+4.2 \mathrm{~mm}$ from the dura. The injection lasted for $2 \mathrm{~min}$ and the needle was left in place for $8 \mathrm{~min}$ at the end of injection. At the same time, 


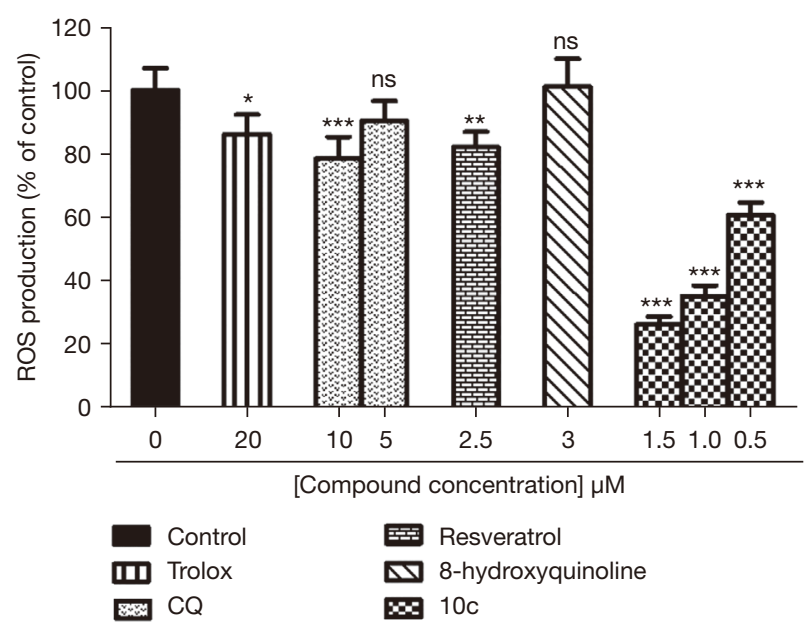

Figure 2 Inhibition of t-BuOOH-induced ROS production by trolox, CQ, resveratrol, 8-hydroxyquinoline, and compound 10c determined by DCFH-DA. Data was presented as mean \pm SD minimally from 3 independent experiments and was expressed as percent of the control (untreated with compound). Three independent experiments were performed in sextuplicate. Statistical comparisons with the control were performed with GraphPad Prism 5.0 software by one-way ANOVA, followed by Dunnett's multiple comparison test (levels of significance: *, $\mathrm{P}<0.05$; **, $\mathrm{P}<0.01 ;{ }^{* *}, \mathrm{P}<0.001$, ns $=$ not significant $)$. ROS, reactive oxygen species; CQ, chelator clioquinol.

sham rats were injected with saline following the same experimental procedure. The animals were transferred to individual cages after the surgery. Rats in the sham group and model group were intragastric administrated with $0.5 \%$ CMC-Na solution $(4 \mathrm{~mL} / \mathrm{kg})$, for 28 consecutive days, once per day, CQ group and 10c group were intragastric administrated with CQ $(21 \mathrm{mg} / \mathrm{kg})$, and $10 \mathrm{c}(35 \mathrm{mg} / \mathrm{kg})$ for the 10c group once per day, respectively.

\section{Morris water maze test}

The Morris water maze test was performed on day 29 for 6 days. Firstly, rats received visible-platform training for 5 consecutive days ( 4 trials/day), with the platform placed in a different location every time. Then, rats were allowed to swim to a flag-mounted platform above the water. The rat was permitted to stay on the platform for $15 \mathrm{~s}$, and if it located the platform within $120 \mathrm{~s}$, the seeking time (namely the escape latency) and the path it took were recorded. Otherwise, the rat was directed onto the platform and the searching time was recorded as $120 \mathrm{~s}$. To assess memory retention, a spatial probe trial was performed $24 \mathrm{~h}$ after the last visible-platform trial. The platform was removed from the pool and the rats had $120 \mathrm{~s}$ to swim to locate the platform. The number of rats crossing the former platform and the time spent in the target quadrant were used to indicate the level of memory retention that occurred after learning.

\section{Statistical analysis}

Data were presented as mean \pm standard deviation, and results were compared using a one-way ANOVA method with a Fisher LSD post-hoc comparison. A significant difference was defined as $\mathrm{P}<0.05$, and a highly significant difference was defined as $\mathrm{P}<0.01$.

\section{Results}

\section{Intracellular antioxidant activity against exogenous ROS}

Oxidative stress-induced damage has been proven to be a significant event in $\mathrm{AD}$ patients, which is associated with damage to DNA, protein oxidation, and lipid peroxidation. Therefore, the scavenging of ROS by some drugs may be an effective approach for the treatment of $\mathrm{AD}$.

As shown in Figure 2, ROS production of SH-SY5Y cells treated with trolox at $20 \mu \mathrm{M}$ was $86.15 \%$ of the control, indicating that trolox had moderate antioxidant activity. In contrast, compound $10 \mathrm{c}$ exhibited far more potent antioxidant activity than trolox, resveratrol, and CQ (ROS production-10c: $26.23 \%$ of the control at $1.5 \mu \mathrm{M}, 35.13 \%$ of the control at $1 \mu \mathrm{M}$, and $60.63 \%$ of the control at $0.5 \mu \mathrm{M}$; resveratrol: $82.17 \%$ of the control at $2.5 \mu \mathrm{M}$; CQ: $78.52 \%$ of the control at $10 \mu \mathrm{M})$. The strong antioxidant activity of compound 10c further supports it as a promising compound for the treatment of $\mathrm{AD}$.

\section{Neuroprotective effect of $10 c$}

Rotenone and oligomycin A disrupt ATP synthesis by blocking complexes I and $\mathrm{V}$, respectively, of the mitochondrial electron transport chain (18). Rotenone/ oligomycin $\mathrm{A}$ is an efficient experimental method to evaluate endogenous mitochondria-triggered oxidative stress. As shown in Figure 3, with respect to control, cells treated only with Rotenone/oligomycin (R/O) showed a viability of $35.45 \%$, while $10 \mathrm{c}$ could effectively improve cell viability from 1 to $20 \mu \mathrm{M}$ (cell viability-10c: $41.09 \%$ of the control at $1 \mu \mathrm{M}, 51.76 \%$ of the control at $2 \mu \mathrm{M}, 71.58 \%$ 


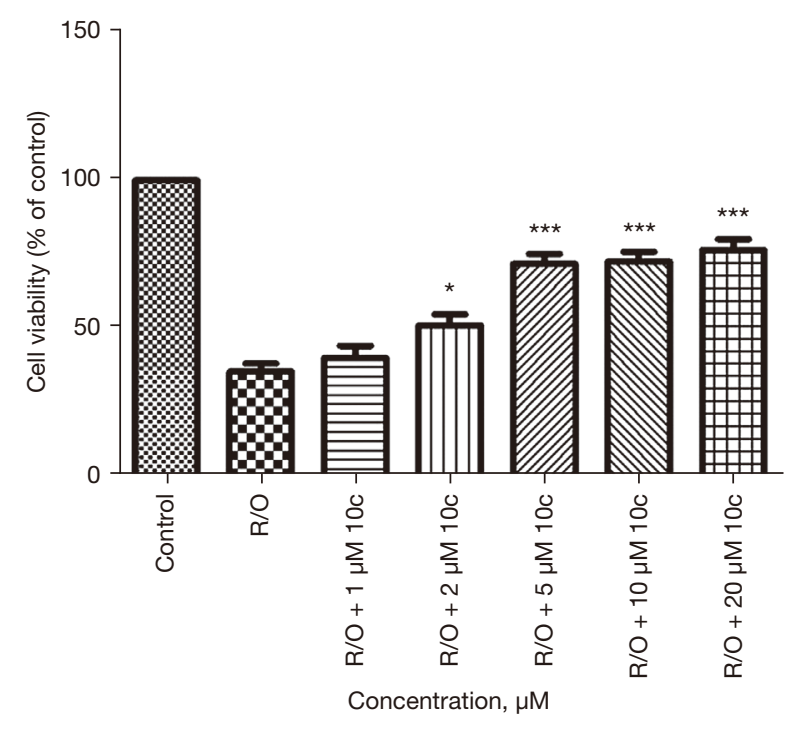

Figure 3 Protection by $10 \mathrm{c}$ against rotenone/oligomycin A (R/O)-induced toxic insult in SH-SY5Y cells. Cell viability was determined by the MTT reduction method. Data was presented as mean \pm SD minimally from 3 independent experiments and was expressed as percent of control. Three independent experiments were performed in sextuplicate. Statistical comparisons of R/O results were performed with GraphPad Prism 5.0 software by oneway ANOVA, followed by Dunnett's multiple comparison test (levels of significance: *, $\mathrm{P}<0.05$; ${ }^{* *}, \mathrm{P}<0.001$ ).

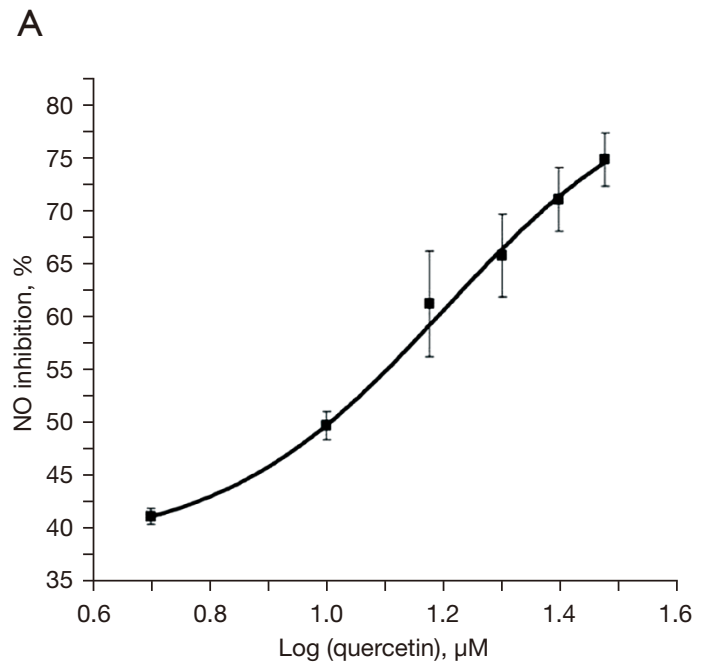

of the control at $5 \mu \mathrm{M}, 72.54 \%$ of the control at $10 \mu \mathrm{M}$, $76.58 \%$ of the control at $20 \mu \mathrm{M})$. Thus, $10 \mathrm{c}$ shows good neuroprotective effects as an endogenous antioxidant in neuroblastoma cells.

\section{Compound 10c suppresses NO level in LPS-induced BV-2 microglial cells}

$\mathrm{NO}$, a proinflammatory mediator, is overexpressed in the neuroinflammatory process $(21,22)$. NO and superoxide cause peroxynitrite formation, which leads to oxidative stress causing cell signaling pathway disruption, cellular dysfunction, and brain cell death $(23,24)$. As shown in Figure 4, the positive control, quercetin, exhibited moderate activity with an $\mathrm{IC}_{50}$ value of $10.00 \mu \mathrm{M}$. Compound $10 \mathrm{c}$ demonstrated good inhibitory activity against $\mathrm{NO}$ production with an $\mathrm{IC}_{50}$ value of $3.10 \mu \mathrm{M}$, suggesting that it may be an efficient agent for the treatment of neurodegenerative diseases with neuroinflammatory involvement.

\section{Compound 10c reduces $I L-1 \beta$ production in vitro}

Neuroinflammation plays an important role in the pathogenesis of $\mathrm{AD}$, and the proinflammatory factor IL-1 $\beta$ plays a central role in immune and inflammatory responses

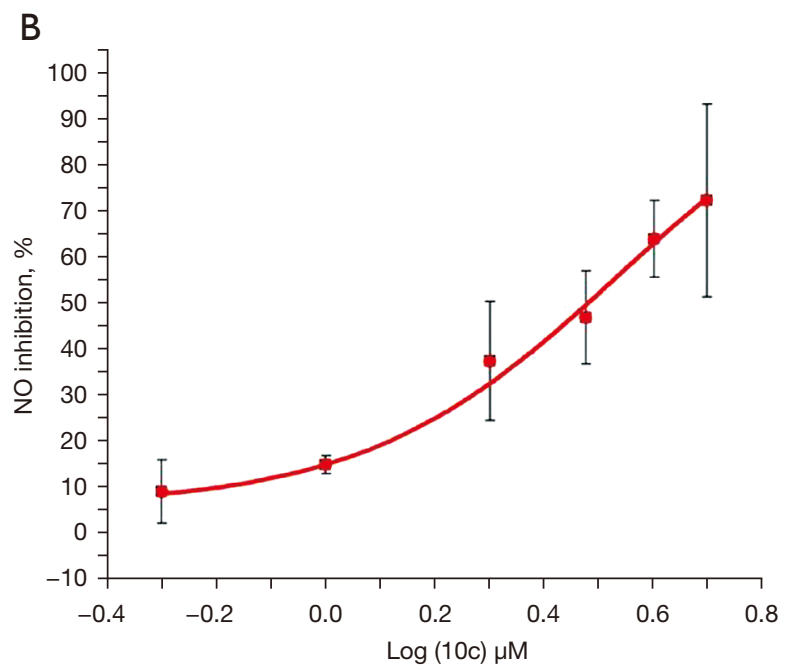

Figure 4 Inhibitory activity against NO production. (A) The inhibitory curves of quercetin (positive control) against LPS-induced NO production in BV-2 cells; (B) the inhibitory curves of 10c against LPS-induced NO production in BV-2 cells. NO, nitric oxide; LPS, lipopolysaccharide. 
$(25,26)$. As shown in Figure 5, 10c effectively reduced the release of IL-1 $\beta$ from 0 to $20 \mu \mathrm{M}$, and it was a potential inhibitor of IL-1 $\beta$ production.

\section{Protective effects of compound $10 \mathrm{c}$ on $A_{\beta_{25-35} \text {-induced }}$ learning and memory dysfunction in rats}

In order to evaluate the therapeutic effect of $10 \mathrm{c}$ in an $\mathrm{AD}$

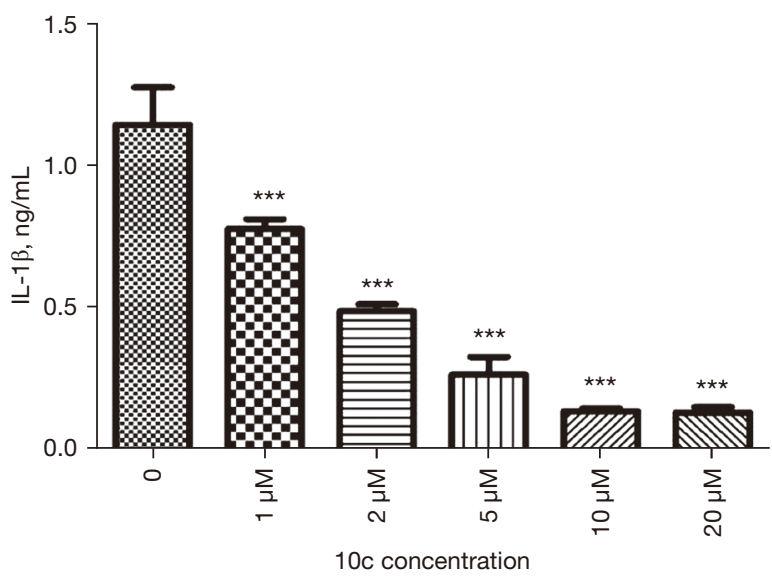

Figure $5 \mathrm{IL}-1 \beta$ secretion. Compound $10 \mathrm{c}$ prevented the increase of IL- $1 \beta$ induced by LPS. Cell culture supernatants were harvested to determine IL- $1 \beta$ secretion by ELISA. Values were presented as mean $\pm \mathrm{SD}$ of 5 independent BV-2 cell replication experiments (levels of significance: $\left.{ }^{* * *}, \mathrm{P}<0.001\right)$. LPS, lipopolysaccharide. animal model, we performed the Morris water maze test to assess $A \beta_{25-35}$-induced learning and memory dysfunction in rats treated with compound 10c (27). CQ was used as the reference compound. As shown in Figure 6A, the number of model group rats who crossed the former platform was $1.9 \pm 1.2$ in the spatial probe trial, which was much less

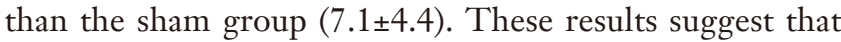
intrahippocampal injection of $\mathrm{A} \beta_{25-35}$ could induce memory and spatial learning deficiency in rats. However, the numbers of rats who crossed the former platform in both the $10 \mathrm{c}(5.7 \pm 1.6)$ and CQ $(5.1 \pm 1.7)$ treatment groups were significantly increased $(\mathrm{P}<0.05)$ compared to the model group. Meanwhile, the results of the time spent in the target quadrant were similar to the numbers of rats crossing the former platform. Compared with the sham group (44.8 \pm $11.1 \mathrm{~s})$, the vehicle-treated model group $(32.7 \pm 4.1 \mathrm{~s})$ showed a significant reduction $(\mathrm{P}<0.05)$ in the time rats spent in the target quadrant (Figure $6 B)$. Both $10 \mathrm{c}(43.8 \pm 5.5 \mathrm{~s})$ and CQ $(44.1 \pm 6.6 \mathrm{~s})$ treatment could significantly prolong the time rats spent in the target quadrant compared to the vehicletreated model group. These results demonstrated that $10 \mathrm{c}$ could alleviate the learning and memory dysfunction of rats induced by $A \beta_{25-35}$ to a certain extent. Compared with well-established transgenic mouse model, the animal model we used in this study may just can mimic the early stage of Alzheimer's disease. The long-term evaluation of 10c in $\mathrm{AD}$ transgenic mouse model would be carried out in our subsequent work.
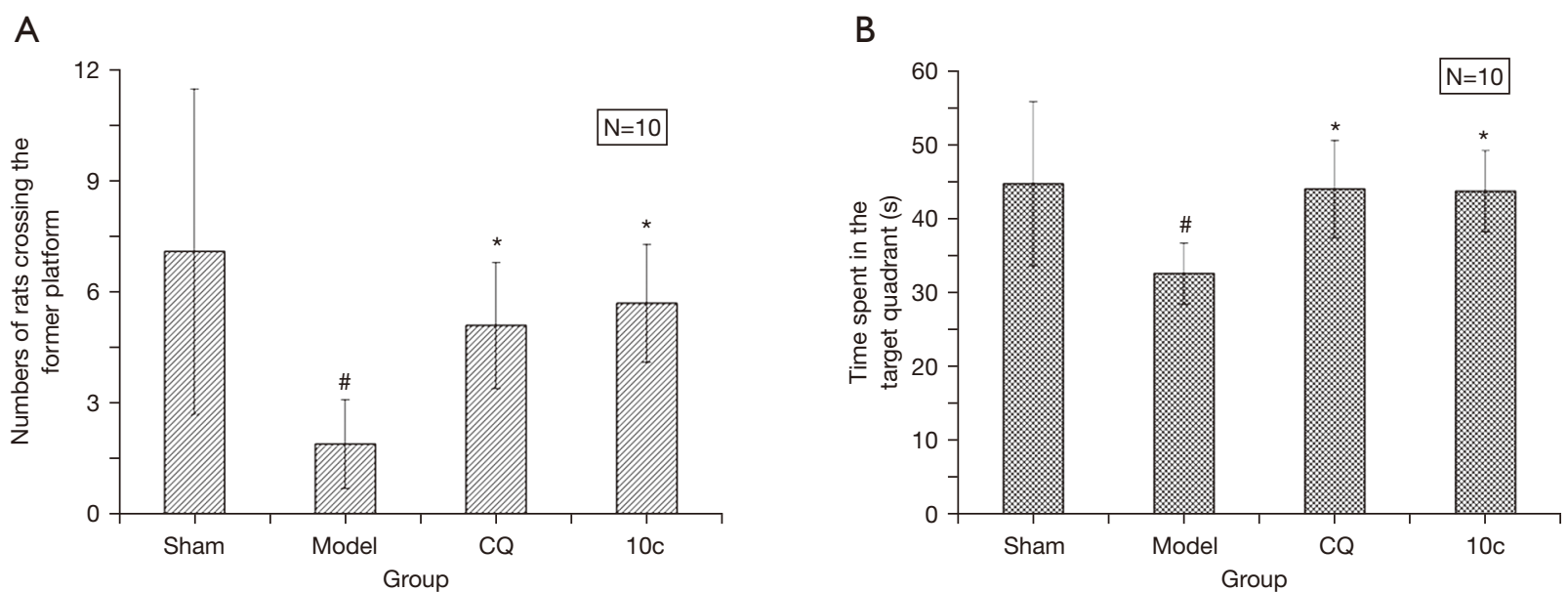

Figure 6 Morris water maze test for rats in the sham group, model group, CQ group, and 10c group. (A) The numbers of rats crossing the former platform in each group in the spatial probe trial; (B) the time each group of rats spent in the target quadrant in the spatial probe trial. ", $\mathrm{P}<0.05$ compared with the sham group; *, $\mathrm{P}<0.05$ compared with the model group (ANOVA for repeated measures). CQ, chelator clioquinol. 


\section{Conclusions}

Based on previous research, the 8-hydroxyquinolineresveratrol derivative 10c was studied for its intracellular antioxidative activities, anti-inflammatory activity, and protective effects on $\mathrm{A} \beta_{25-35}$-induced learning and memory dysfunction in rats. In summary, 10c showed good activity in inhibiting exogenous and endogenous ROS, and could effectively inhibit the release of proinflammatory mediators such as NO and IL-1 $\beta$. Importantly, in vivo tests indicated that $10 \mathrm{c}$ has a good protective effect on the $\mathrm{A} \beta_{25-35}$-induced learning and memory dysfunction of rats. Altogether, compound $10 \mathrm{c}$ exhibited multi-funtional anti-AD activities, further research will focus on the development of compound 10c as a promising new drug for treatment of Alzheimer's disease.

\section{Acknowledgments}

Funding: None.

\section{Footnote}

Reporting Checklist: The authors have completed the ARRIVE reporting checklist. Available at https://dx.doi. org/10.21037/apm-21-1983

Data Sharing Statement: Available at https://dx.doi. org/10.21037/apm-21-1983

Conflicts of Interest: All authors have completed the ICMJE uniform disclosure form (available at https://dx.doi. org/10.21037/apm-21-1983). The authors have no conflicts of interest to declare.

Ethical Statement: The authors are accountable for all aspects of the work in ensuring that questions related to the accuracy or integrity of any part of the work are appropriately investigated and resolved. Animal experiments were performed under a project license (No. 20175000102) granted by the ethics committee of Sun Yat-sen University, in compliance with Chinese national guidelines for the care and use of animals.

Open Access Statement: This is an Open Access article distributed in accordance with the Creative Commons Attribution-NonCommercial-NoDerivs 4.0 International License (CC BY-NC-ND 4.0), which permits the non- commercial replication and distribution of the article with the strict proviso that no changes or edits are made and the original work is properly cited (including links to both the formal publication through the relevant DOI and the license). See: https://creativecommons.org/licenses/by-nc-nd/4.0/.

\section{References}

1. Kepp KP. Bioinorganic chemistry of Alzheimer's disease. Chem Rev 2012;112:5193-239.

2. Zhou WW, Lu S, Su YJ, et al. Decreasing oxidative stress and neuroinflammation with a multifunctional peptide rescues memory deficits in mice with Alzheimer disease. Free Radic Biol Med 2014;74:50-63.

3. Massa F, Meli R, Morbelli S, et al. Serum neurofilament light chain rate of change in Alzheimer's disease: potentials applications and notes of caution. Ann Transl Med 2019;7:S133.

4. Bolognesi ML, Matera R, Minarini A, et al. Alzheimer's disease: new approaches to drug discovery. Curr Opin Chem Biol 2009;13:303-8.

5. Sachdeva AK, Chopra K. Lycopene abrogates A $\beta(1-42)-$ mediated neuroinflammatory cascade in an experimental model of Alzheimer's disease. J Nutr Biochem 2015;26:736-44.

6. Ferretti MT, Bruno MA, Ducatenzeiler A, et al. Intracellular $\mathrm{A} \beta$-oligomers and early inflammation in a model of Alzheimer's disease. Neurobiol Aging 2012;33:1329-42.

7. Nazem A, Sankowski R, Bacher M, et al. Rodent models of neuroinflammation for Alzheimer's disease. J Neuroinflammation 2015;12:74.

8. Bungart BL, Dong L, Sobek D, et al. Nanoparticleemitted light attenuates amyloid- $\beta$-induced superoxide and inflammation in astrocytes. Nanomedicine 2014;10:15-7.

9. Behl C, Moosmann B. Antioxidant neuroprotection in Alzheimer's disease as preventive and therapeutic approach. Free Radic Biol Med 2002;33:182-91.

10. Finkel T, Holbrook NJ. Oxidants, oxidative stress and the biology of ageing. Nature 2000;408:239-47.

11. Sharma P, Jha AB, Dubey RS, et al. Reactive Oxygen Species, Oxidative Damage, and Antioxidative Defense Mechanism in Plants under Stressful Conditions. Journal of Botany 2012;2012:1-26.

12. Praticò D. Oxidative stress hypothesis in Alzheimer's disease: a reappraisal. Trends Pharmacol Sci 2008;29:609-15. 
13. Lee HP, Casadesus G, Zhu X, et al. All-trans retinoic acid as a novel therapeutic strategy for Alzheimer's disease. Expert Rev Neurother 2009;9:1615-21.

14. Wang X, Wang W, Li L, et al. Oxidative stress and mitochondrial dysfunction in Alzheimer's disease. Biochim Biophys Acta 2014;1842:1240-7.

15. Mao F, Yan J, Li J, et al. New multi-target-directed small molecules against Alzheimer's disease: a combination of resveratrol and clioquinol. Org Biomol Chem 2014;12:5936-44.

16. de Los Ríos C, Egea J, Marco-Contelles J, et al. Synthesis, inhibitory activity of cholinesterases, and neuroprotective profile of novel 1,8-naphthyridine derivatives. J Med Chem 2010;53:5129-43.

17. Romero A, Egea J, González-Muñoz GC, et al. ITH12410/SC058: a new neuroprotective compound with potential in the treatment of Alzheimer's disease. ACS Chem Neurosci 2014;5:770-5.

18. Egea J, Rosa AO, Cuadrado A, et al. Nicotinic receptor activation by epibatidine induces heme oxygenase-1 and protects chromaffin cells against oxidative stress. J Neurochem 2007;102:1842-52.

19. Li J, Zeng KW, Shi SP, et al. Anti-neuroinflammatory constituents from Polygala tricornis Gagnep. Fitoterapia 2012;83:896-900.

20. Allan SM, Tyrrell PJ, Rothwell NJ. Interleukin-1 and neuronal injury. Nat Rev Immunol 2005;5:629-40.

21. Liu B, Hong JS. Role of microglia in inflammation-

Cite this article as: Xie J, Su R, Wu D, Qin Y, Yun X. A novel synthetic compound shows antioxidant and anti-inflammatory activity and alleviates cognitive deficits in rats for the treatment of Alzheimer's disease. Ann Palliat Med 2021;10(9):9508-9515. doi: 10.21037/apm-21-1983 mediated neurodegenerative diseases: mechanisms and strategies for therapeutic intervention. J Pharmacol Exp Ther 2003;304:1-7.

22. Robinson MA, Baumgardner JE, Otto CM. Oxygendependent regulation of nitric oxide production by inducible nitric oxide synthase. Free Radic Biol Med 2011;51:1952-65.

23. Dong Z, Gu Q, Cheng B, et al. Natural nitric oxide (NO) inhibitors from Aristolochia mollissima. RSC Adv 2014;4:55036-43.

24. Carret-Rebillat AS, Pace C, Gourmaud S, et al. Neuroinflammation and $A \beta$ accumulation linked to systemic inflammation are decreased by genetic PKR down-regulation. Sci Rep 2015;5:8489.

25. Lippai D, Bala S, Petrasek J, et al. Alcohol-induced IL-1 $\beta$ in the brain is mediated by NLRP3/ASC inflammasome activation that amplifies neuroinflammation. J Leukoc Biol 2013;94:171-82.

26. Sims JE, Smith DE. The IL-1 family: regulators of immunity. Nat Rev Immunol 2010;10:89-102.

27. Wang Z, Wang Y, Wang B, et al. Design, Synthesis, and Evaluation of Orally Available Clioquinol-Moracin M Hybrids as Multitarget-Directed Ligands for Cognitive Improvement in a Rat Model of Neurodegeneration in Alzheimer's Disease. J Med Chem 2015;58:8616-37.

(English Language Editor: C. Betlazar-Maseh) 